DOI: 10.1515/linpo-2015-0004

\title{
Prosodic vowel lengthening in a spontaneous speech corpus of Vimeu Picard
}

\author{
Eric Halicki
}

West Liberty University, eric.halicki@gmail.com

\begin{abstract}
Eric Halicki. Prosodic vowel lengthening in a spontaneous speech corpus of Vimeu Picard. The Poznan Society for the Advancement of Arts and Sciences, PL ISSN 0079-4740, pp. 77-87

The goal of this paper is to present findings about vowel lengthening at morpho-syntactically defined prosodic boundaries. The data come from a corpus of spontaneous speech from Vimeu Picard, a GalloRomance language. A total of 10672 vowel durations are measured, and 5336 vowel ratios are calculated, providing data for the prosodic word, clitic group, phonological phrase, intonational phrase, and the utterance. A general increase in vowel duration is observed as one ascends the prosodic hierarchy, without adjusting for rate of speech. Significant differences in vowel ratio are found between the clitic group and all other phrases, the prosodic word and the intonational phrase, the phonological phrase and the intonational phrase, and the intonational phrase and the utterance. Contrary to what was expected, vowel ratios at the utterance edge were found to be significantly shorter than vowel ratios at the intonational phrase edge. This may be because pauses are greater for the utterance than for the intonational phrase.
\end{abstract}

Keywords: phonology, phonetics, Prosodic Hierarchy, phonological phrase, intonational phrase, utterance, vowel length, vowel ratio, Picard, French

\section{Introduction}

Prosodic levels, such as the syllable, foot, phonological phrase, accentual phrase, etc., have been of great interest to phonologists for over thirty years. Studies generally follow one of two schools: the phonetic and the morpho-syntactic. Using the phonetic approach to prosodic structure, researchers such as Jun \& Fougeron (2000; 2002), Mertens (1993), Pierrehumbert (1980), and Vaissière \& Michaud (2006) define prosodic levels based on phonetic cues, primarily intonational structure. On the other hand, the morpho-syntactic school, whose proponents include Liberman \& Prince (1977), Nespor \& Vogel (1982; 1986), Selkirk (1980; 1984; 1986), and Inkelas \& Zec (1996), tends to use morphological and syntactic concepts to delimit prosodic units. For example, a prosodic word may or may not extend over a morpheme boundary in a given language. Or, a phonological phrase may be able to incorporate material on its non-recursive side (i.e. the specifier position) but not on its recursive side. Despite these differences in approach, it has been acknowledged that both groups of analysts are making reference to the same linguistic reality, a single prosodic structure (cf. Jun 1998; 
Steedman 1991). This is particularly apparent when someone within the morpho-syntactic framework posits vowel lengthening or consonant strengthening as secondary evidence for a prosodic boundary or when a researcher from the phonetic school relies on the idea of content words (as opposed to functional words) or to other syntactic information.

Notwithstanding the study of French prosodic boundaries by Gendrot \& Gerdes (2009), who used a phonetic approach, little research has been done on quantifying the phonetic cues occurring at each prosodic level. Furthermore, previous research of this nature using entirely spontaneous speech corpora is virtually non-existent. With these gaps in the research, the present study has three primary goals. First, I seek to provide much needed data from spontaneous speech to the overall study of prosodic structure. My line of inquiry, then, is in keeping with the objectives of Jun (1998), but with the starting point of the morphosyntactician or the prosodic phonologist. Secondly, I hope to enrich the linguistic literature with the first vowel lengthening study of Vimeu Picard, a vanishing Romance language. Lastly, I would like to quantify the effect of prosodic structure on an important phonetic cue, namely vowel ratio or relative vowel duration across morpho-syntactically defined boundaries. Vowel ratio, to my knowledge, has never been studied in this way before and yet is a useful tool when looking at spontaneous speech because of the difficulties of adjusting for rate of speech across a large corpus. Moreover, it makes intuitive sense that speakers are relying on vowel ratio or relative vowel duration to determine prosodic boundary though this may not be the only phonetic cue that plays a role.

\section{The prosodic hierarchy in Vimeu Picard}

The most well known morpho-syntactic approach to prosody is that of Nespor \& Vogel $(1982 ; 1986)$. They define seven distinct levels: the syllable $(\sigma)$, the foot $(\Sigma)$, the phonological word or prosodic word (PW), the clitic group (CG), the phonological phrase (PPhr), the intonational phrase (I), and the utterance (U). Prosody is structured such that one prosodic level dominates the level below it which in turn dominates the one immediately beneath it, etc. as is shown in the following figure:

\section{Prosodic Hierarchy ${ }^{1}$}

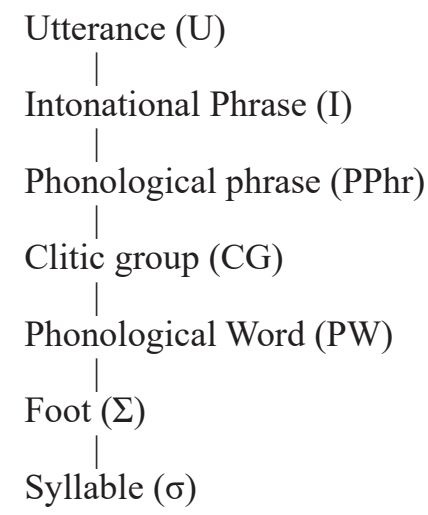

1 This figure is adapted from Nespor \& Vogel (1986: 16). 
The foot and the syllable are not the focus of the present discussion. For the remaining five levels, I shall adopt standard definitions used by those working within Nespor \& Vogel's $(1982 ; 1986)$ framework.

The two lowest levels of the hierarchy that I shall look at are the most easily defined. The prosodic word, the lowest level I shall consider, is for the sake of this work defined as a stem with all its prefixes and suffixes. Following Vogel (1999; 2008), prosodic words must be minimally bi-moraic: one heavy syllable or two light syllables in length. So, prosodic words can include prepositions which satisfy the minimality constraint and for which there is some semantic content but do not include function words such as determiners (for example ch/éch 'the') or small prepositions with very little meaning (for example d/éd 'of'), nor do prosodic words contain the sub-minimal class of morphemes known as clitics. These are contained in the next highest level, the clitic group. Once again relying on Vogel (1999; 2008), I define the CG as containing a clitic and the prosodic word which is its host. Functional words are incorporated, along with CG's into phonological phrases.

The domain of the phonological phrase itself proves more controversial in the literature than either the clitic group or the prosodic word. Nespor \& Vogel (1986) propose that a phonological phrase consists of a lexical head (i.e. $\mathrm{N}^{0}, \mathrm{~V}^{0}$, etc.) and all material on the non-recursive side of the lexical head, within its maximal projection. If the lexical head has a complement, restructuring may or may not take place. So, in (2a), the functional word and clitics to the left of the lexical head form a single phonological phrase, while in (2b) a phonological phrase boundary is found between the lexical head and the non-complementary material to its right.

(2) (a) [qu'à ll'érbéyeu $]_{\mathrm{PPhr}}$ than + to +3 sgDO+look at again 'than to look at it again'

(b) [éch tchuré $]_{\mathrm{PPhr}}[\text { i vnoait }]_{\mathrm{PPhr}}$ 'this priest, he used to come'

Researchers debate however as to what kind of complement can undergo phonological phrase restructuring. Nespor \& Vogel (1986) posit that only non-branching complements, i.e. those containing a single prosodic word, can optionally participate in restructuring as in (3) while Ghini (1993) and Rao (2007) have argued that branching complements can also optionally take part in the process as in (4).

(3) (a) Expected phonological phrasing

$[\text { les miettes }]_{\mathrm{PPhr}}$ [éd pain $]_{\mathrm{PPhr}}$

'the crumbs of bread'

(b) Phonological phrase restructuring with non-branching complement

[les miettes éd pain $]_{\mathrm{PPhr}}$

'the crumbs of bread'

(4) (a) Expected phonological phrasing

[eine cope $]_{\text {PPhr }}$ [éd piot lives $]_{\mathrm{PPhr}}$

'a trove of little books' 
(b) Phonological phrase restructuring with branching complement

[eine cope éd piot lives $]_{\mathrm{Phhr}}$

'a trove of little books'

For the purposes of this study, I shall accept the traditional definition of the phonological phrase given above and leave the question open now as to whether there is a branching restriction on phrase restructuring.

Even within the morpho-syntactic approach, definitions for the two highest levels of the prosodic hierarchy, the intonational phrase and the utterance, generally rely to some extent on features that are neither syntactic nor morphological. The intonational phrase groups together all adjacent phonological phrases within a syntactic IP and can be thought of as equivalent, in many cases, to one as in (5a). However, as Nespor \& Vogel (1982) point out, an intonational phrase boundary is assumed to exist wherever a pause is inserted so that in a list or after fronted material as in (5b), much smaller intonational phrases are found.

(5) (a) $\quad[\text { ch'est exactement pareil }]_{I}$

'it's exactly the same'

(b) $\quad[\text { ch'est leu-bos }]_{\mathrm{I}}[\text { ch'code postal }]_{\mathrm{I}}$

'It's over there, this zip code'

Intonational phrase restructuring is optionally available for two adjacent intonational phrases within the same utterance though intonational phrase restructuring will not be a focus in the present study. Finally, the utterance for its part contains all adjacent intonational phrases within a sentence, or to use semantic terms, an utterance groups together all intonational phrases that represent a complete thought as in (6).

[Il folloait porter chom malle avec éch sapré poney $]_{\mathrm{U}}[\text { Ech poney il étoait... }]_{\mathrm{U}}$ 'You had to carry the suitcase with this darned poney. The poney was...'

\section{Previous research and hypothesis}

VP phonology shows itself to be highly sensitive to the prosodic hierarchy. Auger (2001), Auger \& Steele (1999), and Steele \& Auger (2002) have demonstrated that wordinitial vowel epenthesis is directly related to prosodic boundary. Likewise, word-final vowel epenthesis is blocked at the highest levels of prosody (cf. Auger 2000; 2010; Auger \& Steele 1999; Steele \& Auger 2002), while these same levels favor the realization of consonants in C/Ø alternations (Auger \& Petrush 2009). So, though no phonetic study of the present kind has ever been conducted for VP, the language's reliance on prosodic domains makes it a good candidate for testing vowel lengthening at boundaries.

Vowel duration has been previously associated as a phonetic cue indicating prosodic boundary. Ghini (1993), Nespor \& Vogel (1986), and Rao (2007) all list vowel lengthening as a prevalent feature of the right edge of the phonological phrase, though do not specifically focus on describing lengthening in their studies. Jun \& Fougeron (2000) and Ueyama (2001) also posit vowel duration as a feature of the right edge of AP's and IP's, the phonetic school's equivalents of the phonological phrase and the intonational phrase respectively. 
No vowel duration studies have previously been conducted for VP, but it is reasonable to look at similar duration studies on French since VP is both historically related to French and shares relevant phonological features, for example ultimate stress, with its sister Gallo-Romance language. Delais-Roussarie (2000) puts the domain for stress and vowel lengthening in French at the right edge of the phonological phrase. According to Nespor \& Vogel's (1986) strict layer hypothesis, then, vowel lengthening and stress ought to be phonetic cues at the intonational phrase and utterance levels as well. Delattre (1966) examines $[\varepsilon / \mathrm{e}]$ in stressed and unstressed positions in different phonological environments and finds that in all segmental environments combined, average unstressed vowel duration is $118 \mathrm{~ms}$ while average stressed vowel duration is found to be $260 \mathrm{~ms}$, about $220 \%$ longer. Since these rhythm groups (to use Delattre's terminology) were separate from each other and not in a continuous speech sample, the question arises as to whether the stressed vowels were, in fact, found at the ends of intonational or phonological phrases. In another study of French, Fant et al. (1991) find an average unstressed vowel length of $63 \mathrm{~ms}$, and in non-prepausal stressed position, the duration is increased on an average of $35 \mathrm{~ms}(55 \%)$ to $98 \mathrm{~ms}$. However, before a pause (i.e. at the end of an intonational phrase), these researchers report an average increase by $80 \mathrm{~ms}(126 \%)$ to $143 \mathrm{~ms}$. Comparing vowel durations across seven vowels with a semi-spontaneous speech corpus, Gendrot \& Gerdes (2009) find that vowel duration increases at the right edge of prosodic units are directly related to position in the prosodic hierarchy, with increasingly longer durations occurring as one moves up the hierarchy. Though this study showed that differences in duration are affected by vowel quality, the actual percent increase in duration from one level to another was similar for most vowels examined. For example, the researchers found that vowel duration for [0] measured approximately $80 \mathrm{~ms}$ at the prosodic word, $110 \mathrm{~ms}$ at the AP, and $150 \mathrm{~ms}$ at the IP while the respective vowel lengths for [a] at these three levels was approximately $60 \mathrm{~ms}, 85 \mathrm{~ms}$, and $115 \mathrm{~ms}^{2}$ Though Gendrot \& Gerdes (2009) do not take note of this specifically nor discuss vowel duration at any length, it is interesting that the percentage increase in vowel duration from prosodic word to AP is $138 \%$ for [o] and $142 \%$ for [a] while the percent increase in duration from AP to IP is $136 \%$ for [o] and $135 \%$ for [a]. In conclusion, given that vowel lengthening is associated with the right edges of prosodic boundaries in French, it is reasonable to expect similar increases in vowel duration at the right edges of phonological phrase boundaries and higher in VP.

Lastly, I would like to briefly discuss vowel ratio or relative duration. In spontaneous speech samples, measuring vowel durations to see if lengthening has taken place can be rather tricky. Wagner (2008) finds that for French, phrase-final vowel durations in fast speech are shorter than phrase-final vowel durations in moderate or slow speech. In fact, our perception of whether speech is fast or slow is linked to lengthening or shortening of vowel durations at the end of prosodic units (cf. Wagner \& Windmann 2009). To complicate matters, a fast speech rate in one language may contain more units of speech per second than what is considered fast speech in another language (Dellwo 2010). So, if a speaker speeds up or slows down his/her rate of speech a number of times during a conversation, without

2 These data are based on a figure from Gendrot \& Gerdes (2009: 201). Because of a misalignment in the original figure, the vowel durations given for the vowel [0] could under an alternative alignment be interpreted as corresponding to the vowel [o]. Regardless, the quality of the vowel makes no difference for the present analysis. 
controlling for speech rate or vowel quality, it becomes difficult to determine when a significant change in duration occurs. An alternative way to capture vowel lengthening, and the one adopted in the present study, is to look at the vowel or syllable ratio, i.e. the relative duration, for a pair of vowels or syllables. Tuisk \& Teras (2009) use this methodology to examine length distinctions in Livonian, which has three degrees of vowel quantity: short, long, and very long. Long vowels, for example, showed syllable duration ratios of 2:1, the first (lengthened) syllable being two times longer than the second syllable while very long vowels showed syllable duration ratios of $3: 1$, the first syllable being three times longer than the second syllable (Tuisk \& Teras 2009). Aasmäe (2005), in a study of idiolectal differences between speakers of Erzya, compares vowel ratios of stressed-vowels-to-unstressed-vowels between groups of speakers and found smaller ratios of between 1.03-1.21.

Given the previous work on French, it makes sense to posit that vowel durations in VP will also progressively increase with increasing prosodic level. In terms of vowel ratio, one would expect to see near 1:1 ratios below the domain for stress, i.e. the phonological phrase, and progressively larger ratios at the phonological phrase, intonational phrase, and utterance levels.

\section{Methodology}

The majority of the corpus comes from personal interviews conducted by a researcher not involved in the present paper from the period 1996-2000 and from radio programs in VP from 1989. Five speakers, all male ranging in age from mid-thirties to late-sixties, from the Vimeu region of northeastern France were used for the study. In total, the corpus lasts approximately 445 minutes. Analogue recordings were digitized into MP3 files and analyzed in Praat (Boersma \& Weenink 2010).

Vowel durations for 10672 vowels, in 5336 pairs, were measured manually using Praat. Vowel pairs were selected from a range of segmental environments occurring word-intially and word-finally:_C,_V, CC_C, CC_V, C_CC, V_CC, C_CC. The segmental inventory of VP resembles that of French, though the phonotactics differ from French. Halicki (2011) lists 21 consonants: ${ }^{3}[\mathrm{p}],[\mathrm{t}],[\mathrm{k}],[\mathrm{b}],[\mathrm{d}],[\mathrm{g}],[\mathrm{f}],[\mathrm{v}],[\mathrm{s}],[\mathrm{z}],[\mathrm{J}],[3],[\mathrm{m}],[\mathrm{n}],[\mathrm{n}],[\mathrm{y}],[\mathrm{r}],[1]$, [w], [u], [j]. Given the number of consonants, I do not control for the effects of any particular consonant or any class of consonants on duration or vowel ratio. In addition to singleton consonants, the segmental inventory also includes geminates: some of them derived (cf. Cardoso 1998) and some them underlying (cf. José \& Auger 2005). I code all surface geminates as CC sequences. VP's vocalic system is also similar to French with 14 surface vowels according to Halicki (2011) though José \& Auger (2004) argue that surface nasal vowels are

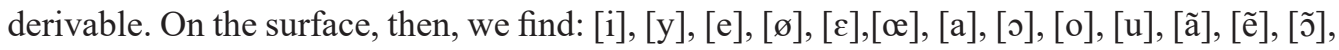
[थ̃]. Some of these vowels are rare in the corpus, so I have only looked at the durations of the three most common: [a], [i], and [u]. To be clear, for all vowel ratios calculated, the first vowel in a pair of vowels occurred on the left edge of a prosodic boundary and the second on the right. The vowel ratio of the first vowel in the pair to the second was calculated, and statistical analyses were conducted using SPSS and MedCalc.

3 Vasseur (1996) posits two more: [d3] and [t]]. However, Dawson (2008) argues that these affricates can be derived from stop-fricative sequences. 
The definitions used for each prosodic boundary are those discussed in the previous section. I inserted prosodic boundaries manually. I was confronted with ambiguous parsing at the three highest levels of prosody whenever phrase restructuring could occur. The most serious and widespread parsing ambiguities occurred at the phonological phrase boundary. Because the theoretical literature disagrees on phonological phrase restructuring, I coded for three distinct types of unit: the phonological phrase with no complement (PPhr), the phonological phrase with a non-branching complement $\left(\mathrm{PPhr}_{\mathrm{NBC}}\right)$, and the phonological phrase with a branching complement $\left(\mathrm{PPhr}_{\mathrm{BC}}\right)$. The intonational phrase and the utterance did not present the same type of problem since both required a pause. It was generally clear when phrases were utterances rather than intonational phrases restructured into the same utterance due to repetition of a content word as in (6) or the use of discourse markers such as donc 'therefore', bon ben 'so', or alors 'so' that show a clear movement from one complete thought to another.

\section{Results}

Let us first consider vowel durations for all vowels combined and for [a], [u], and [i] in particular. In (7), mean vowel durations appear according to prosodic level.

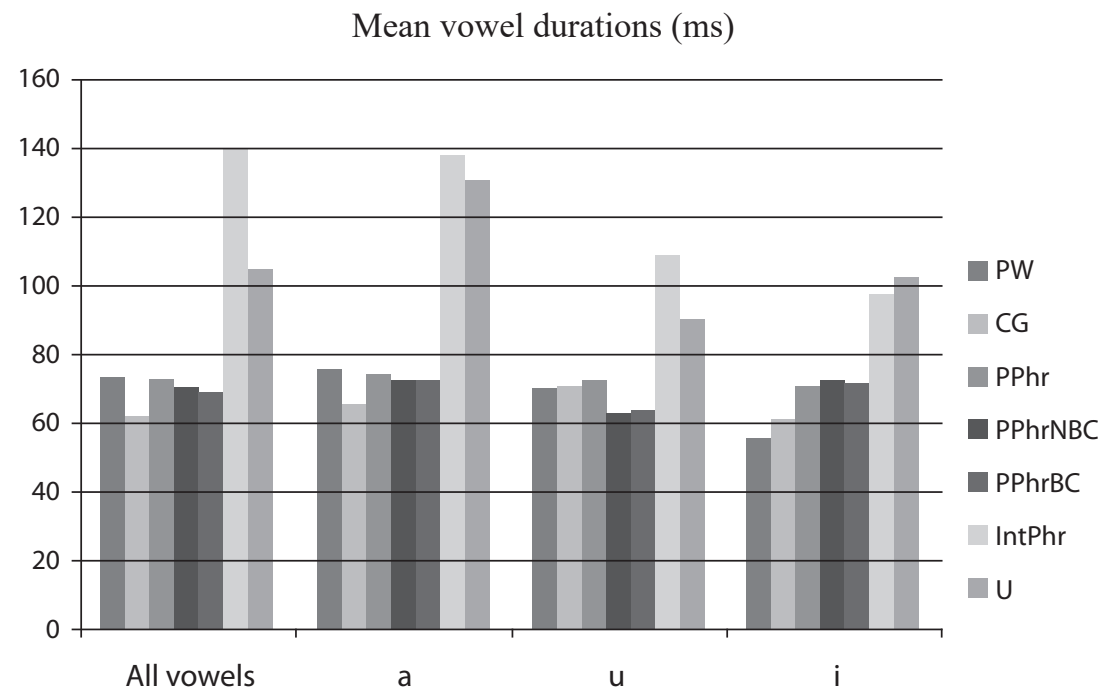

Most notably, vowel durations are longest (except in the case of [i]) at the right edge of the intonational phrase boundary; even the right edge of the utterance showing shorter vowels. For all vowels combined, the difference in duration between the vowels at the edges of the intonational phrase and the utterance is significant $(\mathrm{t}=3.467$, d.f. $=1730, \mathrm{p}=.0005)$. Likewise, the right edge of the utterance shows a signficantly longer vowel than any level 
besides the intonational phrase. ${ }^{4}$ Below the intonational phrase, no clear increase in duration at phrase-boundary occurs, although a pattern similar to that observed by Gendrot \& Gerdes (2009), i.e. with progressively increasing durations, appears to surface for [i].

In (8), we see a clearer distinction of prosodic level according to vowel ratio as confirmed by an ANOVA $(\mathrm{F}=130.393$, d.f. between $=6$, d.f. within $=5329, \mathrm{p}<.001)$, though not necessarily what we had expected. As was the case in (7), the utterance boundary has a signficantly lower vowel ratio overall than is observed for the intonational phrase boundary $(\mathrm{t}=3.948$, d.f. $=1730, \mathrm{p}=.0001)$ and the utterance boundary ratio is significantly higher than ratios found at any level other than the intonational phrase. ${ }^{5}$ Interestingly, the vowel ratio found at the boundary of two $\mathrm{PPhr}_{\mathrm{NBC}}$ units was significantly shorter than for either the $\operatorname{PPhr}(t=3.309$, d.f. $=2358, \mathrm{p}=.001)$ or the $\operatorname{PPhr}_{B C}(t=4.217$, d.f. $=2969, \mathrm{p}<.0001)$. This and the lack of significant difference in vowel ratio between the boundaries of the PW and the $\operatorname{PPhr}_{\mathrm{NBC}}(\mathrm{t}=.930$, d.f. $=2251, \mathrm{p}=.3523)$ suggest that a phonological phrase boundary (and hence vowel lengthening) is more likely to occur between a lexical head and its branching complement than between a lexical head and its non-branching complement. Neither the $\mathrm{PPhr}$ or the $\mathrm{PPhr}_{\mathrm{BC}}$ have significantly larger ratios than the prosodic word, ${ }^{6}$ however. A last surprising find is that the CG boundary vowel ratio measures significantly lower than either the prosodic word $(\mathrm{t}=2.629$, d.f. $=277, \mathrm{p}=.009)$ or the $\mathrm{PPhr}_{\mathrm{NBC}}(\mathrm{t}=2.074$, d.f. $=2036$, $\mathrm{p}=.0382)$.

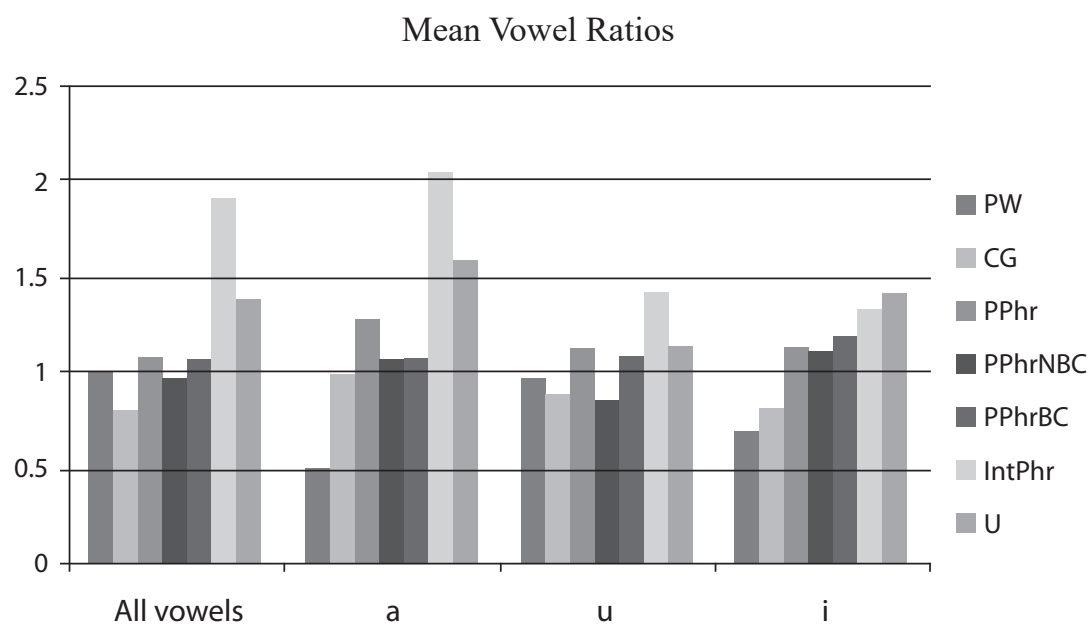

4 The t-tests reveal significant differences between $\mathrm{U}$ and PW $(\mathrm{t}=7.803$, d.f. $=424, \mathrm{p}<.0001)$, $\mathrm{U}$ and $\mathrm{CG}(\mathrm{t}=4.845$, d.f. $=209, \mathrm{p}<.0001), \mathrm{U}$ and PPhr $(\mathrm{t}=9.764$, d.f. $=531, \mathrm{p}<.0001), \mathrm{U}$ and $\mathrm{PPhr}_{\mathrm{NBC}}(\mathrm{t}=13.401$, d.f. $=2183, \mathrm{p}<.0001)$, $U$ and $\operatorname{PPhr}_{B C}(t=11.424$, d.f. $=1142, p<.0001)$.

5 We see significant differences in mean ratio between the $U$ and PW $(t=6.852$, d.f. $=424, p<.0001)$, the $\mathrm{U}$ and $\mathrm{CG}(\mathrm{t}=4.830$, d.f. $=209, \mathrm{p}<.0001)$, the $\mathrm{U}$ and PPhr $(\mathrm{t}=5.563$, d.f. $=531, \mathrm{p}<.0001)$, the $\mathrm{U}$ and $\mathrm{PPhr} \mathrm{NBC}$ $(\mathrm{t}=9.970$, d.f. $=2183, \mathrm{p}<.0001)$, the $U$ and $\operatorname{PPhr}_{B C}(t=6.334$, d.f. $=1142, \mathrm{p}<.0001)$.

6 The t-test statistics are for the PW and the PPhr $(\mathrm{t}=1.551$, d.f. $=599, \mathrm{p}=.1214)$ and for the $\mathrm{PW}$ and $\mathrm{PPhr}$ $(\mathrm{t}=1.407, \mathrm{~d} . \mathrm{f} .=1210, \mathrm{p}=.1595)$ 
In sum, five levels of vowel length based on mean vowel ratios at prosodic boundary are found in VP, though statistical significance is not achieved between each type of phonological phrase and the prosodic word. The longest lengthening, of about 1.9:1 for all vowels combined, occurs at the intonational phrase boundary followed by a ratio of about 1.4:1 at the utterance boundary. A slightly longer vowel is found at the $\mathrm{PPhr}$ and $\mathrm{PPhr}_{\mathrm{BC}}$ (of about $1.1: 1$ ) than at the end of the clitic group (about .8:1) or at the end of the prosodic word (about 1:1), though this last difference is not significant. Both the $\mathrm{PPhr}$ and the $\mathrm{PPhr}_{\mathrm{BC}}$ have significantly longer vowels than the $\mathrm{PPhr}_{\mathrm{NBC}}$. The clitic group's vowel ratio is lower than at any other level. I have summarized these differences in vowel length in (9).

$\begin{array}{lc}\text { Degrees of vowel lengthening in VP } \\ \text { Prosodic level } & \text { Approximate vowel ratio } \\ \mathrm{I} & 1.9: 1 \\ \mathrm{U} & 1.4: 1 \\ \mathrm{PPhr} \text { and } \mathrm{PPhr}_{\mathrm{BC}} & 1.1: 1 \\ \mathrm{PW} \text { and } \mathrm{PPhr}_{\mathrm{NBC}} & 1: 1 \\ \mathrm{CG} & .8: 1\end{array}$

6. Discussion

This vowel lengthening study has raised at least three questions. First, though I expected to see the largest ratios at the utterance and intonational phrase levels, it was surprising that intonational phrase boundary vowels were significantly longer than those at the utterance boundary. A possible explanation for this may be that other phonetic cues are more pronounced at the utterance edge, reducing reliance on vowel lengthening to distinguish the level. Pause lengths at the utterance level have been found to be significantly longer than those at the intonational phrase level in VP, as in Halicki (2011), while the interaction of pause and vowel lengthening lies outside the scope of the present study. A second problem that arises is that the PPhr and the $\mathrm{PPhr}_{\mathrm{BC}}$ boundaries do not produce vowels significantly longer than the prosodic word. This could possibly result from not controlling for segmental environment. Vasseur $(1996,1998)$ notes that the vowel in a final syllable in VP is lengthened before certain voiced consonants: [b], [3], [r], and [z], a phenomenon that could be skewing the data. Nonetheless, the idea implicit in studies like Aasmäe (2005) and Tuisk \& Teras (2009) is that over a large sample of vowel ratios, the effect of non-prosodic vowel lengthening is (at least partially) diminished. Only further research controlling for final consonant lengthening can determine the effect this has on vowel ratios in VP. Lastly, it is somewhat odd that vowels at the end of the clitic group are shorter than even those at the end of prosodic words. Because this difference is significant, it does offer support for the existence of the clitic group as a prosodic constituent. ${ }^{7}$ In other words, very short vowels distinguish this prosodic level. Given that the clitic group can be the site of vowel reduction in languages, this analysis may find some support. It could also be that the existence of a clitic, in and of itself, sets apart the clitic group, making vowel lengthening a superfluous phonetic cue. As was discussed in Halicki (2011), this could explain why utterance-boundary vowels are shorter.

\footnotetext{
For opposing views see Inkelas \& Zec (1996) and Vogel (2008).
} 


\section{Conclusion}

This paper is part of a larger project to quantify phonetic cues at the edges of morphosyntactically defined prosodic boundaries. Unlike previous studies, I have relied on a spontaneous speech corpus and have concentrated on vowel ratio data rather than vowel duration. I have shown that there are progressively longer vowels as one ascends the prosodic hierarchy. In fact, significant differences in vowel ratio occur between the CG and all other levels, between both the $\mathrm{PPhr}$ and $\mathrm{PPhr}_{\mathrm{BC}}$ and the $\mathrm{PPhr}_{\mathrm{NBC}}$, between the $\mathrm{U}$ and all other levels, and between the I and all other levels. Future studies should examine pause length at the highest levels of prosody and the intonational patterns associated with each prosodic phrase in VP.

\section{Acknowledgements}

I wish to thank Julie Auger for access to her corpus of Vimeu Picard as well as her many insights on its grammar over the years. I am also grateful to the anonymous reviewers and to my colleagues Shannon Halicki and Kristi Howard for their comments on a previous version of this paper. All remaining errors are mine.

\section{References}

Aasmäe, Niina. 2005. Duration variability in Erzya: Stressed and unstressed nuclei in idiolects. Linguistica Uralica 4. 264-278.

Auger, Julie. 2000. Phonology, Variation, and Prosodic Structure: Word-Final Epenthesis in Vimeu Picard. In Fontana, Josep M. \& Mcnally, Louise \& Turell, M. Teresa \& Vallduvi, Enric. (eds.), Proceedings of the First International Conference on Language Variation in Europe (ICLaVE), Barcelona, 14-24. Barcelona: Universitat Pompeu Fabra.

Auger, Julie. 2001. Phonological variation and Optimality Theory: Evidence from word-initial vowel epenthesis in Vimeu Picard. Language Variation and Change 13. 253-303.

Auger, Julie. 2010. Structure prosodique et épenthèse vocalique en picard. Paper presented at Phonolex, Toulouse. Auger, Julie \& Petrush, Rebecca. 2009. Phonologie et prosodie en picard. Tout o, ch'est point toute! Handout of paper presented at the Congrès annuel de l'ACL. March 25, 2009.

Auger, Julie \& Steele, Jeffrey. 1999. Vowel Epenthesis in Vimeu Picard: A Preliminary Investigation. University of Pennsylvania Working Papers in Linguistics 6(2). 1-15.

Boersma, Paul \& Weenink, David. 2010. Praat: doing phonetics by computer. www.praat.org.

Cardoso, Walcir. 1998. The domain of across-word regressive assimilation in Picard: An optimality-theoretic account. Southwest Journal of Linguistics 17(2). 1-21.

Dawson, Alain. 2008. Palatalization and non-palatalization of velar stops in Picard: Opacity and sympathetic candidates in real life. Paper presented at 5th Old World Conference in Phonology, Toulouse. January 23-26.

Delais-Roussarie, Élisabeth. 2000. Vers une nouvelle approche de la structure prosodique. Langue francaise 126. 92-112.

Delattre, Pierre. 1966. Studies in French and Comparative Phonetics: Selected Papers in French and English. The Hague: Mouton.

Dellwo, Volker. 2010. Influences of speech rate on the acoustic correlates of speech rhythm: An experimental phonetic study based on acoustic and perceptual evidence, Universität Bonn. (Ph.D. dissertation.)

Fant, Gunnar \& Kruckenberg Anita \& Nord, Lennart. 1991. Durational correlates of stress in Swedish, French, and English. Journal of Phonetics 19. 351-365. 
Gendrot, Cédric \& Gerdes, Kim. 2009. Prosodic hierarchy and spectral realization of vowels in French. Actes d'IDP 09. 191-205.

Ghini, Mirco. 1993. $\Phi$-formation in Italian: a new proposal. Toronto Working Papers in Linguistics 12. 41-78.

Halicki, Eric. 2011. Phonology and the Prosodic Hierarchy in Picard, Indiana University. (Ph.D. dissertation.)

Inkelas, Sharon \& Zec, Draga. 1996. Syntax-phonology Interface. In Goldsmith, John A. (ed.). 1996. The Handbook of Phonological Theory, 535-549. Cambridge: Blackwell Publishers.

José, Brian \& Auger, Julie. 2004. (Final) nasalization as an alternative to (final) devoicing: The case of Vimeu Picard. In José, Brian \& de Jong, Ken (eds.). 2004. IULC Working Papers Online 4-04. [https://www.indiana.edu/ iulcwp/pdfs/], 1-44.

José, Brian \& Auger, Julie. 2005. Geminates and Picard pronominal clitic allomorphy. Catalan Journal of Linguistics 4. 127-154.

Jun, Sun-Ah. 1998. The Accentual Phrase in the Korean prosodic hierarchy. Phonology 15. 189-226.

Jun, Sun-Ah \& Fougeron, Cécile. 2000. A Phonological Model of French Intonation. In Botinis, Antonis (ed.), Intonation: Analysis, Modeling, and Technology, 209-242. Amsterdam: Kluwer.

Jun, Sun-Ah \& Fougeron, Cécile. 2002. Realizations of accentual phrase in French intonation. Probus 14. 147172.

Liberman, Mark \& Prince, Alan. 1977. On Stress and Linguistic Rhythm. Linguistic Inquiry 8. 249-336.

Mertens, Piet. 1993. Accentuation, Intonation, et Morphosyntaxe. Travaux de linguistique 26. 21-69.

Nespor, Marina \& Vogel, Irene. 1982. Prosodic domains of external sandhi rules. In van der Hulst, Harry \& Smith, Norval. (eds.), The Structure of Phonological Representations: Part I, 225-255. Dordrecht: Foris.

Nespor, Marina \& Vogel, Irene. 1986. Prosodic Phonology. Dordrecht: Foris Publications.

Pierrehumbert, Janet. 1980. The Phonology and Phonetics of English Intonation, MIT. (Ph.D. dissertaion.)

Rao, Rajiv. 2007. On the Phonological Phrasing Patterns in the Spanish of Lima, Perú. Southwest Journal of Linguistics 26(1). 81-111.

Selkirk, Elisabeth. 1980. The Role of Prosodic Categories in English Word Stress. Linguistic Inquiry 11(3). 563605.

Selkirk, Elisabeth. 1984. Phonology and Syntax: The Relation between Sound and Structure. Cambridge, MA: MIT Press.

Selkirk, Elisabeth. 1986. On Derived Domains in Sentence Phonology. Phonology Yearbook 3. 371-405.

Steedman, Mark. 1991. Structure and Intonation. Language 67(2). 260-296.

Steele, Jeffrey \& Auger, Julie. 2002. A Constraint-Based Analysis of Intraspeaker Variation: Vocalic Epenthesis in Vimeu Picard. In Satterfield, Teresa \& Tortora, Christina \& Cresti, Diana (eds.), Current Issues in Romance Languages: Selected Papers from the 29th Linguistic Symposium on Romance Languages, 317-335. Amsterdam: Benjamins.

Tuisk, Tuuli \& Teras, Pire. 2009. The role of duration ratios and fundamental frequency in spontaneous Livonian. Linguistica Uralica 45. 241-252.

Ueyama, Motoko. 2001. An experimental study of vowel duration in phrase-final contexts in Japanese. Oceanic Linguistics 40(2). 307-323.

Vaissière, Jacqueline \& Michaud, Alexis. 2006. Prosodic constituents in French: a data-driven approach. In Fónagy, Ivan \& Kawaguchi, Yuji \& Moriguchi, Tsunekazu (eds.). 2006, Prosody and Syntax, 47-64. Amsterdam: Benjamins.

Vasseur, Gaston. 1996. Grammaire des Parlers Picards du Vimeu (Somme) avec considération spéciale du dialecte du Nibas. Abbeville: F. Paillart.

Vasseur, Gaston. 1998. Dictionnaire des Parlers Picards du Vimeu (Somme) avec considération spéciale du dialecte du Nibas. 2e édition. Paris: SIDES.

Vogel, Irene. 1999. Subminimal Constituents in Prosodic Phonology. In Hannahs, S. J. \& Davenport, Michael (eds.), Issues in Phonological Structure: Papers from an International Workshop, 249-267. Amsterdam: Benjamins.

Vogel, Irene. 2008. The Morphology-Phonology Interface: Isolating to Polysynthetic Languages. Acta Linguistica Hungarica 55(1-2). 205-226.

Wagner, Petra. 2008. The rhythm of language and speech: Constraints, models, metrics, and applications. Online publication. [http://pub.uni-bielefeld.de].

Wagner, Petra \& Windmann, Andreas. 2009. No time to lose? Time shrinking effects enhance the impression of rhythmic 'isochrony' and fast speech rate. Proceedings of Interspeech. [http://pub.uni-bielefeld.de]. 
